\title{
Radiological evaluation of the fetal face using three-dimensional ultrasound imaging
}

This article was published in the following Dove Press journal:

Reports in Medical Imaging

30 November 2012

Number of times this article has been viewed

\author{
Marcel Bäumler ${ }^{1-3}$ \\ Michèle Bigorre ${ }^{1,4}$ \\ Jean-Michel Faure ${ }^{1,5}$ \\ 'CHU Montpellier, Centre de \\ Compétence des Fentes Faciales, \\ Hôpital Lapeyronie, Montpellier, \\ ${ }^{2}$ Clinique du Parc, Imagerie de la \\ Femme, Castelnau-le-Lez, ${ }^{3}$ Cabinet \\ de Radiologie du Trident, Lunel, \\ ${ }^{4} \mathrm{CHU}$ Service de Chirurgie Plastique \\ Pédiatrique, Hôpital Lapeyronie, \\ Montpellier, ${ }^{5} \mathrm{CHU}$ Montpellier, \\ Service de Gynécologie-Obstétrique, \\ Hôpital Arnaud de Villeneuve, \\ Montpellier, France
}

\begin{abstract}
This paper reviews screening and three-dimensional diagnostic ultrasound imaging of the fetal face. The different techniques available for analyzing biometric and morphological items of the profile, eyes, ears, lips, and hard and soft palate are commented on and briefly compared with the respective bi-dimensional techniques. The available literature supports the use of three-dimensional ultrasound in difficult prenatal diagnostic conditions because of its diagnostic accuracy, enabling improved safety of perinatal care. Globally, a marked increase has been observed in the accuracy of three-dimensional ultrasound in comparison with the bidimensional approach. Because there is no consensus about the performance of the different three-dimensional techniques, future studies are needed in order to compare them and to find the best technique for analysis of each of the respective facial elements. Universal prenatal standards may integrate these potential new findings in the future. At this time, the existing guidelines for prenatal facial screening should not be changed.
\end{abstract}

Keywords: prenatal three-dimensional ultrasound, prenatal screening, prenatal diagnosis, cleft lip and palate, fetal profile, retrognathism

\section{Introduction}

Prenatal ultrasound of the fetal face is viewed by parents as a means of obtaining a first picture of their baby. The discovery of fetal anomaly is followed by fear and culpability, as parents suffer the loss of the expected normal infant. ${ }^{1}$ When this anomaly is localized to the face of the fetus, the emotional distress might naturally be more amplified for parents because of the additional social and psychological impact. At the time of detection, the clinician is confronted with a difficult situation because the parents are not really capable of absorbing information or understanding their child's anomaly. Therefore, the clinician's words should be as cautious as possible. Some countries propose a multidisciplinary approach and family follow-up in the event of fetal malformation. This depends on the clinician having the opportunity to talk to parents in the setting of a prenatal multidisciplinary counseling team consisting of obstetricians, sonographers, geneticists, pediatricians, radiologists, and surgeons. The team evaluates the malformation and its extension, a potential syndromic association, indications for other imaging techniques such as three-dimensional ultrasound or magnetic resonance imaging (MRI), indications for invasive diagnostic procedures, and finally prognostic considerations.

Prenatal imaging of the fetal face has been the subject of several publications in the past. Bidimensional ultrasound remains the type of imaging which is recognized to be the most cost-effective and useful screening method for facial malformations.
Correspondence: Marcel Bäumler Clinique du Parc, Imagerie de la Femme, 50 rue Emile Combes,

34170 Castelnau-le-Lez, France

Tel +33467453693

Fax +3346745 3987

Email baeumler@free.fr 
In many developed countries, prenatal screening ultrasound is subject to professional recommendations. The screening principle is based on interest in detection of an illness with regard to its incidence, the therapeutic consequences, and costeffectiveness. ${ }^{2}$ Since the advent of prenatal three-dimensional ultrasound techniques for medical purposes in 1973, many efforts have been made to visualize the fetal face. ${ }^{3}$

As a result of research, the role of three-dimensional ultrasound visualization of the face in screening and in particular diagnostic procedures has been highlighted. ${ }^{4}$ For prenatal screening, the standard recommendation is to visualize the tip of the nose, nostrils, and upper and lower lip. ${ }^{5,6}$ These elements are sufficiently visible on bi-dimensional ultrasound imaging, and there are no guidelines for use of three-dimensional ultrasound for this purpose. A recent French recommendation mandates supplementary visualization and analysis of the fetal profile and eyes for diagnostic purposes. $^{7}$

If the prenatal counseling team is confronted by a facial malformation in a baby, every member of the team needs to transmit precise information about the diagnosis and prognosis to the parents. The precision depends on evaluation being as complete as possible. Prenatal ultrasound lies at the heart of such an assessment, because all decisions that follow can be adequate only if the imaging is accurate. Genetic counseling, indications for invasive diagnostics, indications for termination of pregnancy, postnatal development, and follow-up are necessarily different if there are associated malformations. ${ }^{1}$

Prenatal imaging by bi-dimensional ultrasound is considered the gold standard for prenatal screening and diagnosis, although past publications point to increasing accuracy in diagnostics when three-dimensional ultrasound is used. ${ }^{8}$

MRI plays a role in the recognition of facial anomalies, especially for localization of facial tumors of the surface and buccal cavity, ${ }^{9}$ in fetal ocular measurements, ${ }^{10}$ and assessment of cleft lip alone and cleft lip and palate. ${ }^{11,12}$ Computed tomography can complete the diagnosis in the event of suspected bony anomalies of the fetal skull. ${ }^{13}$ In the following sections, we review the three-dimensional ultrasound methods used for visualization of the ears, eyes, bony and surface profile, lips and nostrils, and hard and soft palate.

\section{Imaging of the ears}

When the prenatal counseling team is confronted with an environmental, familial, or genetic risk, especially in the event of various associated symptoms seen on ultrasound, such as polyhydramnion and other facial anomalies, ${ }^{14}$ evaluation of the biometry and morphology of the ears is interesting. Biometric nomograms have been established by bi-dimensional and three-dimensional ultrasound for the length of the ears. ${ }^{15}$ Other authors report that ear length is nearly one-third the biparietal diameter throughout pregnancy. ${ }^{16}$

A biometric anomaly such as microtia is a congenital anomaly, characterized by a small, abnormally shaped auricle. The prevalence of microtia is $0.8-4.2$ per 10,000 births, and the condition is more common in males. Anotia is characterized by the absence of the external ear. Microtia-anotia is usually accompanied by a narrow, blocked, or absent ear canal. ${ }^{17}$ Microtia-anotia can occur either as an isolated defect or in association with other defects. A genetic or environmental etiology might be found, and microtia-anotia is a component of isotretinoin, thalidomide, alcohol, and diabetes embryopathy. It occurs with single gene disorders, such as Treacher-Collins syndrome (Figure 1), as part of seemingly nonrandom patterns of multiple defects, such as Goldenhar syndrome, ${ }^{18}$ branchiootorenal and branchiootic syndromes, and oculoauricular syndrome, as well as in the context of chromosomal syndromes, such as trisomy $18 .{ }^{19-21}$ A recent publication recommends using three-dimensional ultrasound and the combination of three ear growth indexes (length, width, and ear area) to enhance the detection rate of aneuploidy in comparison with bi-dimensional ultrasound alone. ${ }^{20}$ However, fetal ear measurements should not be used as a solitary ultrasonographic parameter in identifying aneuploid fetuses. ${ }^{20}$

Morphological analytical descriptions of the ears are not available in the prenatal literature. The rotation of the ears has been described to have an influence on increased risk of autosomal trisomies. ${ }^{22}$ However, such extraordinarily specific evaluations should be the subject of further studies. Accurate three-dimensional ultrasound analysis of morphology can help the practitioner to identify and describe the pathology, and to relate it to a syndromic entity.

\section{Imaging of the eyes}

The interorbital diameter of the fetal eye increases from $8.2 \mathrm{~mm}$ at 11 weeks' gestational age (GA) to $37.6 \mathrm{~mm}$ at $35 \mathrm{GA}$. The interorbital to biparietal diameter ratio decreases from 0.52 at $11 \mathrm{GA}$ to 0.42 at $35 \mathrm{GA}^{23}$ The extraorbital diameter increases from $15 \mathrm{~mm}$ at $11 \mathrm{GA}$ to $50 \mathrm{~mm}$ at $35 \mathrm{GA}$, and the interocular diameter increases from $7 \mathrm{~mm}$ at $11 \mathrm{GA}$ to $18 \mathrm{~mm}$ at $35 \mathrm{GA}^{24}$ Three-dimensional approaches evaluate the interorbital diameter with precision. ${ }^{25}$ The volume of the eyeball has positive correlations with gestational age and biparietal diameter. The following index using 


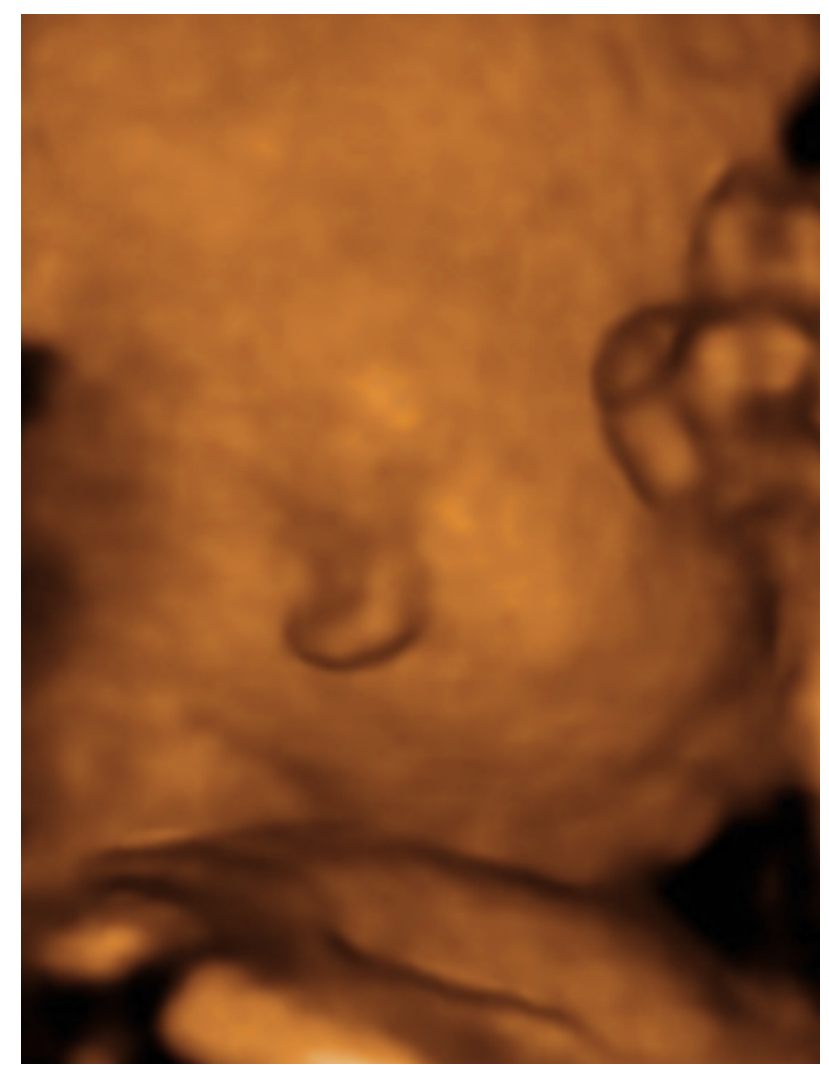

Figure I Three-dimensional ultrasound of microtia in a case of Treacher-Collins syndrome at 24 weeks of gestation.

the biparietal diameter has been proposed: square of the eyeball $=-0.180+0.187$ biparietal diameter. ${ }^{26}$

When analysis of the eyes is required, several syndromes and associations can be involved. Anomalies such like hypotelorism, hypertelorism, microphthalmia, exopthalmos, cyclopia, and cataract can prompt the prenatal diagnostic team to investigate for a syndromic association. The eyes are visible in a bi-dimensional ultrasound axial approach. Three-dimensional ultrasound might improve analysis of biometric anomalies and the anatomy of the eyes, lenses, or orbits. An axial acquisition seems to render the best results, but sagittal acquisition planes can be used in the case of prone fetuses. ${ }^{27}$ Prenatal biometric nomograms have been established by three-dimensional ultrasound in order to analyze microphthalmia. Microphthalmia or anophthalmia demonstrates biometric anomalies of the globe in the axial view through the expected level of the orbits. The most common causes of unilateral anophthalmia are Goldenhar syndrome and trisomy $13 .{ }^{28}$ Microphthalmia should prompt chromosomal analysis as well as a search for associated biometric or anatomic anomalies.

Hypertelorism is associated with a variety of syndromes and conditions. Hypotelorism is associated with generally severe abnormalities, such like holoprosencephaly.
Cataract is indicated by a double echogenic ring inside the orbit. Infectious or genetic etiologies are usual. ${ }^{28}$ Dacrocystocele is a dilatation of the lacrimal system secondary to ductal obstruction; in prenatal life, a typical anechogenic round mass is apparent medially to the orbit and usually of smaller diameter than that of the orbit. Three-dimensional ultrasound also allows determination of the degree of intranasal extension and swelling below the medial canthal area. It is typically bilateral and isolated. Spontaneous in utero restitutio ad integrum has been described. ${ }^{29}$

\section{Imaging of the profile}

When searching for facial anomalies or associated syndromes, investigation of the fetal profile is a fundamental part of the morphological evaluation. Detection of an anomaly is essential because it can help in the diagnosis of genetic disorders or chromosomal abnormalities. Adequate analysis of an anomaly involving the profile is a challenge for the prenatal counseling team, even for experienced practitioners.

Bi-dimensional ultrasound visualization of the profile is a part of the first trimester screening scan, ie, visualization of crown rump length and nuchal translucency. The skill necessary to obtain an adequate view in later pregnancy is commonly available and realized, but is not required by minimal screening programs. Some authors propose a reference axis with the transducer parallel to the long axis of the nose and at about 45 degrees to the echogenic line of the palate. ${ }^{30}$ Previous studies have used qualitative methods, but a more quantitative and objective approach may be useful. Three-dimensional ultrasound has been used to complement bi-dimensional ultrasound for evaluation of the fetal profile. ${ }^{31}$ Studies have investigated the additional value of three-dimensional ultrasound. ${ }^{32}$

Analysis of nasal bone length, prefrontal thickness, frontomaxillary facial angle, maxilla-nasion-mandible angle, nose length (distance between nasion at intersection of the frontal bones and nasal bones and upper anterior corner of maxilla), nose protrusion (distance between pronasale landmark and line used for nose-length measurement perpendicular to nose length line), distance between pronasale and subnasale landmarks, philtrum length, facial height (distance from nasion to lower anterior corner of the mandible) can lead the prenatal counseling team to adjust diagnostic and prognostic considerations. ${ }^{33}$

Nasal bone length is obtained by bi-dimensional ultrasound measurement of the nasal bone from one end to the other. The optimal way to measure its length or its absence is to take a 90 degree angle of insonation to the prenasal skin 
and a 45 degree angle to the palate. ${ }^{34}$ There is progressive overestimation of nasal bone length when measuring in the parasagittal and oblique views compared with measurements taken in the exact mid sagittal plane. When measured in the exact mid sagittal plane and care is taken to exclude the frontal bone, three-dimensional ultrasound measurements of the nasal bone are systematically smaller than those reported using bi-dimensional ultrasound. Three-dimensional ultrasound might allow more exact acquisition of the strict mid sagittal plane by post-acquisition correction. ${ }^{35}$

A small nose is a common facial feature of individuals with trisomy $21 .{ }^{36}$ First-trimester nasal bone length has been proposed to be a component of aneuploidy screening. ${ }^{37}$ Further, in $62.1 \%$ of fetuses with trisomy 21 , the nasal bones were divergent, whereas in 131 of 135 (97.0\%) euploid fetuses, the bones were entirely fused in the midline. ${ }^{38,39}$

Nasal bone hypoplasia had a sensitivity and specificity of $49 \%$ and $92 \%$, respectively, for diagnosis of trisomy 21 , compared with $61 \%$ and $84 \%$, respectively, for the biparietal diameter/nasal bone index. ${ }^{40}$ Absence of nasal bones is associated with a higher risk of Down syndrome than delayed ossification. Subtle ossification patterns may be less distinguishable on bi-dimensional ultrasound compared with three-dimensional ultrasound. ${ }^{41}$

Prefrontal thickness increases with gestation from a mean of $2.4 \mathrm{~mm}$ at 16 weeks to $4.6 \mathrm{~mm}$ at 24 weeks. Fetuses with trisomy 21 tend to show an increased prefrontal thickness. Studies report $70 \%$ sensitivity for trisomy 21 . The landmarks defining the acquisition plane can be identified by bi-dimensional ultrasound, but the three-dimensional ultrasound multiplanar mode might enable more accurate measurement. ${ }^{42}$

Both prefrontal thickness and nasal bone length show growth with gestation, with less pronounced growth for nasal bone length after 28 weeks. ${ }^{35}$ In normal fetuses, the mean prefrontal thickness and nasal bone length increase between 15 and 33 weeks' gestation from $2.3 \mathrm{~mm}$ to $6.1 \mathrm{~mm}$ and from $3.3 \mathrm{~mm}$ to $9.6 \mathrm{~mm}$, respectively. The prefrontal thickness to nasal bone length ratio is stable throughout gestation, with a mean of 0.61 (ranging from 0.48 to 0.80 from the 5 th to 95 th percentiles, respectively). In fetuses with trisomy 21 , mean prefrontal thickness and nasal bone length increase between 14 and 34 weeks from $3.0 \mathrm{~mm}$ to $9.2 \mathrm{~mm}$ and from $1.9 \mathrm{~mm}$ to $7.8 \mathrm{~mm}$, respectively. The prefrontal thickness to nasal bone length ratio is higher than in normal fetuses, but also stable throughout gestation, with a mean of $1.50(95 \%$ confidence interval 1.20-1.80). Seventy-seven percent of fetuses with trisomy 21 have a prefrontal thickness above the
95 th percentile, and $67 \%$ have a nasal bone length below the 5 th percentile. All fetuses with trisomy 21 have a prefrontal thickness to nasal bone length ratio above the 95 th percentile, with a detection and false-positive rate for trisomy 21 corresponding to $100 \%$ and $5 \%$, respectively. ${ }^{43}$

Evaluation of the profile might be available at the levels of the profile surface and bony structures of the forehead. An objective evaluation might be more feasible for bony structures than for surface structures. The bony structures and their ratios and angles do not seem to change significantly during pregnancy, ${ }^{35}$ and craniofacial growth remains linear throughout this time. ${ }^{44}$

In three-dimensional ultrasound studies, the frontomaxillary angle has been proposed to quantify the analysis of the profile. ${ }^{37}$ In the mid sagittal view of the fetal face, the palate is visible as a single homogeneously hyperechogenic rectangular structure at at the first trimester screening scan. In the second and third trimester, there are two echogenic structures, the inferior one representing the palate and the superior one representing the vomer. For measurement of the frontomaxillary facial angle, the first ray is drawn along the superior edge of the palate and the second ray from the upper anterior corner of the maxilla extending to the external surface of the frontal bone. ${ }^{45}$

A common phenotypic feature of individuals with trisomy 21 is a flat face. Thus, a three-dimensional ultrasound method for quantifying the flat face of fetuses with trisomy 21 has been described. ${ }^{45}$ Another tentative to point out an objective three-dimensional ultrasound analysis of the profile has been proposed by the construction of the maxilla-nasion-mandible angle. ${ }^{46}$ The angle is defined as the angle between the intersection of the maxilla-nasion and the mandible-nasion lines in the exact mid sagittal plane. The mean angle seems to be 13.5 degrees and does not change during pregnancy. It might be above the 95th percentile (17 degrees) in the case of retrognathia, and below the 5 th percentile (10 degrees) in syndromes accompanied by a flat face, such like trisomy 21 , achondroplasia, or Gorlin syndrome (Figure 2). In this situation, mandible growth is judged relative to the profile and not according to the growth of its rami. The most common pathology of the profile described in prenatal life may be retrognathia. ${ }^{47} \mathrm{Mul}-$ tiple syndromes are potentially associated with retrognathia. The most common are Pierre-Robin syndrome (Figure 3), Goldenhar syndrome, Treacher-Collins syndrome, velocardiofacial syndrome, and trisomies 13 and $18 .{ }^{48}$ In general, the risk of an adverse outcome is elevated when a prenatal diagnosis of retrognathia is made. ${ }^{28}$ 


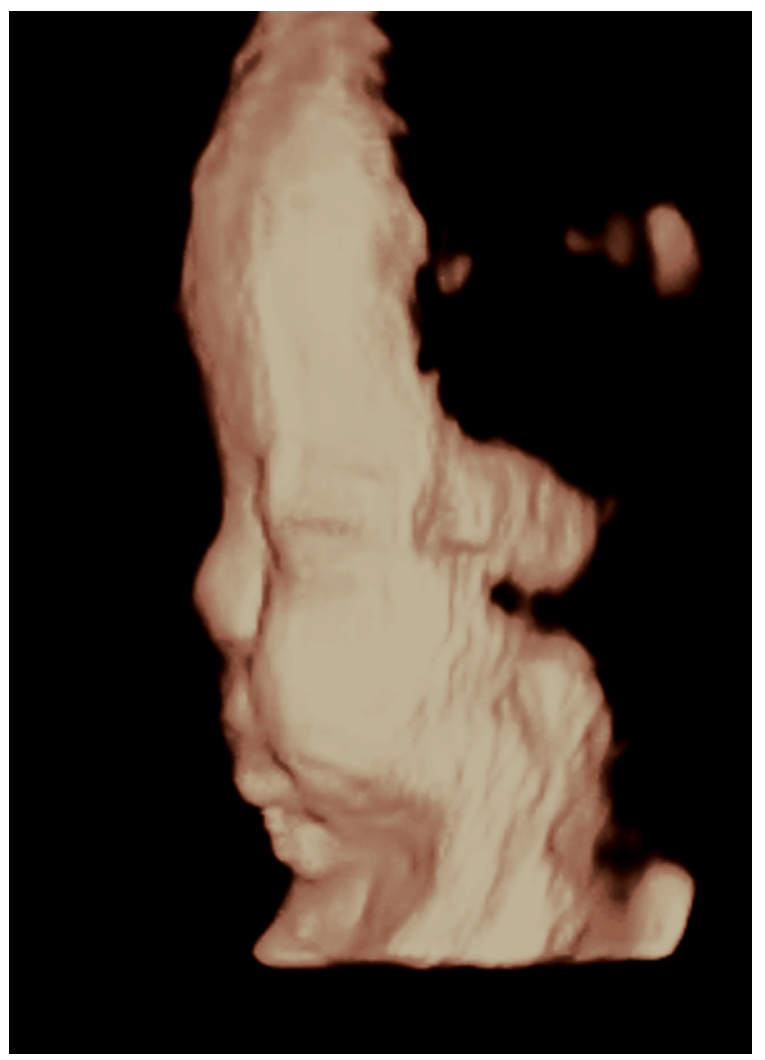

Figure 2 Three-dimensional ultrasound of the profile in a case of Gorlin syndrome at 33 weeks of gestation.

The fetal mandible can be evaluated by measurement of the biometry of the mandibular rami and the relationship of the jaw to the profile. Biometric nomograms exist especially for evaluation of the length and symmetry of the rami. ${ }^{49-51}$ Axial bi-dimensional ultrasound acquisition throughout the totality of both rami allows measurement of the mandible index, ie, the quotient between the diameter linking the two bases of the corpus and the distance between the symphysis menti and its diameter. Using this index, retrognathia might be detectable. ${ }^{52}$ Another biometric approach is the mandibular ratio with gestational age. ${ }^{53}$ Three-dimensional ultrasound techniques have been described in the axial acquisition plane,${ }^{54}$ and normative data values have been established. ${ }^{55}$

\section{Imaging of the lips and nostrils}

In some countries, minimal ultrasound screening guidelines recommend bi-dimensional ultrasound visualization of the nose tip, nostrils, and upper and lower lips. ${ }^{6,56,57} \mathrm{~A}$ bidimensional ultrasound view is considered to be sufficient to detect the most common facial malformation, ie, cleft lip. ${ }^{58}$ In France, such guidelines have existed since 2005. ${ }^{6}$ Publications prior to that date report a sensitivity for detection of facial anomalies of $18 \%-74 \% .{ }^{59-63}$ However, the different reports

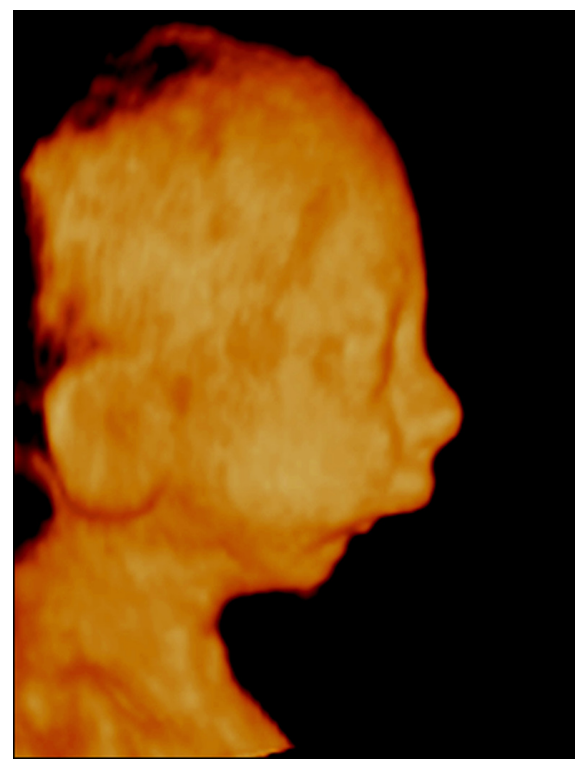

Figure 3 Three-dimensional ultrasound of the profile in a case of Pierre-Robin syndrome at 26 weeks of gestation.

suffer from discrepancies in their study design. After 2005, there are no statistical sources reporting detection rates of cleft lip. Professional imperatives obviously require a 100\% detection rate within this minimal screening program. Threedimensional ultrasound does not play any role in scientific reviews concerning screening for cleft lip. However, threedimensional ultrasound might be helpful and eventually more rapid when there are difficulties in obtaining accurate bi-dimensional ultrasound images of the fetal mouth. ${ }^{61}$

\section{Imaging of the hard palate}

Maxilla and palatine bone constitute the hard palate. The velum and uvula constitute the soft palate. This anatomical classification $^{64}$ differs from the embryological classification which distinguishes between the primary (hard palate anterior to incisive fossa) and secondary (hard and soft palate posterior to incisive fossa) palate. ${ }^{65}$ Diagnostic conditions which may lead the practitioner to visualize the hard palate might include the following: when a cleft lip is screened for in the mid trimester scan, information about the maxilla and the palatine bone is required in order to make an accurate decision as to whether there is an association with a cleft of the alveolar ridge of the maxilla, with a cleft of both the alveolar ridge of the maxilla and the palatine bone (cleft lip and palate), or with a cleft of the palatine bone without cleft of the alveolar ridge of the maxilla. Further, in the event of polymalformative syndromes, polyhydramnion, or a familial history of cleft of the palatine bone, information about the integrity of the fetal palate is required. 
When there is cleft lip, the incidence of cleft lip and palate is approximately one per $1000 .{ }^{58}$ However, it might be more frequent in the fetal population since a considerable number of fetuses with cleft lip and palate are affected by associated abnormalities, which might be accompanied by intrauterine demise. ${ }^{66}$

In the case of cleft lip, the probability of isolated cleft lip is $15 \%$, that of cleft of the alveolar ridge of the maxilla is $6 \%$, and that of cleft lip and palate is $75 \%$. In $1 \%$ of cases of cleft lip, cleft of the palatine bone occurs without cleft of the alveolar ridge of the maxilla. ${ }^{58}$ The present authors report one single case of a cleft lip associated to a cleft of the palatine bone without cleft of the alveolar ridge of the maxilla among 126 facial clefts examined over a period of eight years from 2004 to 2012 (unpublished personal observation). Three percent of cases are represented by complex facial clefts, as classified by Tessier. ${ }^{67}$ The risk of associated genetic karyotypic anomalies and associated malformations is elevated when the hard palate is also cleft. ${ }^{58}$ Further, the functional, esthetic, orthodontic, and surgical follow-up will depend on the diagnosis.

Bi-dimensional ultrasound diagnosis of cleft lip and palate was described for the first time in $1981 .{ }^{68}$ Since then, several publications have reported improvements using different techniques in the imaging of cleft of the alveolar ridge of the maxilla, cleft lip and palate, and cleft of the palatine bone. ${ }^{69-74}$ Three-dimensional ultrasound seems to perform better than bi-dimensional ultrasound in the diagnosis of cleft anomalies. ${ }^{8,62,75-77}$

Ultrasound visualization of the maxilla and palatine bone suffers with several technical difficulties. The alveolar ridge of the maxilla (primary palate) is visible by axial bidimensional acquisition; ${ }^{78}$ on the other hand, structures that are posterior to the alveolar ridge are theoretically invisible by ultrasound as a consequence of reduced axial resolution and posterior shadowing. However, when the sonographer smoothly inclines the ultrasound probe into the cranial or caudal axial direction, shadowing can be avoided and the secondary palate might be identified. Therefore, bi-dimensional ${ }^{79}$ and three-dimensional ${ }^{80}$ ultrasound studies use the axial view to enable accurate visualization of the normal entire hard palate. Other studies suggest possible visualization of both the normal and cleft hard palate using sagittal, ${ }^{71}$ oblique, ${ }^{74}$ or coronal ${ }^{81,82}$ three-dimensional ultrasound.

Past publications have reported variable visualization rates and accuracy for the different techniques cited above. This difference might be due to inhomogeneous and nonstandardized study designs which do not distinguish clearly between three-dimensional and bi-dimensional ultrasound, between different study populations, between screening or diagnostic conditions (context bias ${ }^{83}$ ), between cleft lip and cleft of the alveolar ridge of the maxilla, ${ }^{84}$ between cleft lip and palate and cleft of the palatine bone alone, between different terminologies, such as "hard palate" "primary palate" and "secondary palate", between a normal versus a pathological palate, or between different three-dimensional ultrasound techniques. Three-dimensional ultrasound axial, ${ }^{80}$ coronal, ${ }^{81,82}$ sagittal, ${ }^{71}$ and oblique ${ }^{74}$ acquisition planes have been evaluated for imaging of the secondary palate. In the case of cleft lip and palate, the axial, ${ }^{73}$ coronal, ${ }^{82}$ and sagittal ${ }^{71}$ three-dimensional ultrasound techniques have a sensitivity of $97 \%, 90 \%$, and $100 \%$, respectively. Oblique ${ }^{74}$ techniques need confirmation of their accuracy in the case of a pathological secondary palate. As already indicated, no prospective comparison of these studies has been reported to date. Recent studies evaluating three-dimensional ultrasound techniques do not, at this time, provide a valuable comparison. In consequence, there is no commonly agreed technique for the visualization of the hard palate as yet. ${ }^{69,72}$

The etiopathology of cleft of the palatine bone alone is distinct from that of cleft lip and palate. ${ }^{65,82}$ Visualization of the secondary palate might be of interest when there are signs such as polyhydramnion or retrognathism, ie, fetal signs that orientate to a risk of cleft of the palatine bone. Another diagnostic consideration might be a family history of an isolated cleft of the palatine bone. Our team has found that axial threedimensional ultrasound has high sensitivity and specificity for norma ${ }^{80}$ and cleft hard palate. ${ }^{73}$ We also found this technique to be accurate in a case of isolated cleft of the palatine bone, diagnosed in a woman with a personal history. ${ }^{85}$

Past publications report moderate visualization rates for cleft of the palatine bone in low-risk populations. Published opinions continue to state that both screening for and diagnosis of cleft of the palatine bone remain problematic, and sensitivity is low (35\%), even with adjunctive use of three-dimensional ultrasound ${ }^{86,87}$ However, if the palate is well visualized in the case of an intact palate ${ }^{80}$ (Figure 4) and in the case of cleft lip and palate ${ }^{73,82}$ (Figure 5), it will also be well visualized in the case of cleft of the palatine bone ${ }^{85,88}$ (Figure 6).

\section{Imaging of the soft palate}

Part of a cleft of the palatine bone might be submucosal, and isolated clefts of the soft palate might also exist. Given that the palatine bone is not cleft in some cleft cases, visualization of an intact palatine bone might lead to a false-negative diagnosis. Three-dimensional ultrasound plays an important 


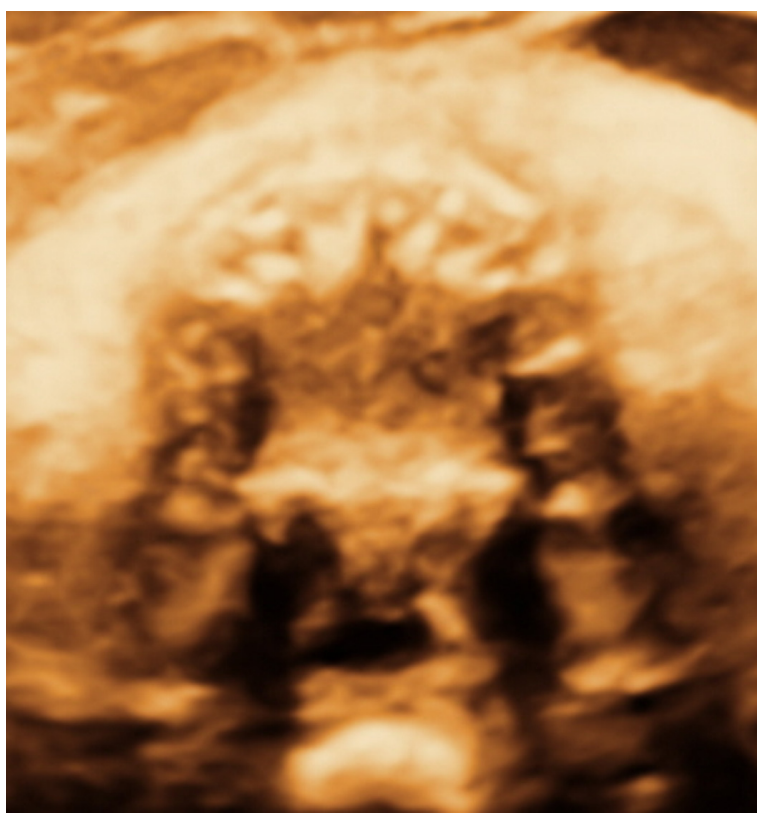

Figure 4 Three-dimensional ultrasound of the intact hard palate at 32 weeks of gestation.

Note: Axial acquisition

role in this situation. Three-dimensional ultrasound visualizes soft tissue better than bi-dimensional ultrasound. Further, the soft palate is inclined about 30 degrees with regard to the palatine bone; ${ }^{89}$ in consequence, post-acquisition threedimensional ultrasound rotation in the axial axis of about 30 degrees allows visualization of the soft palate in its physiological ${ }^{89}$ (Figure 7) or pathological ${ }^{85}$ formation (Figure 8).

\section{Discussion}

In this review, we discuss three-dimensional ultrasound imaging of the fetal face. A comparison with the performance of

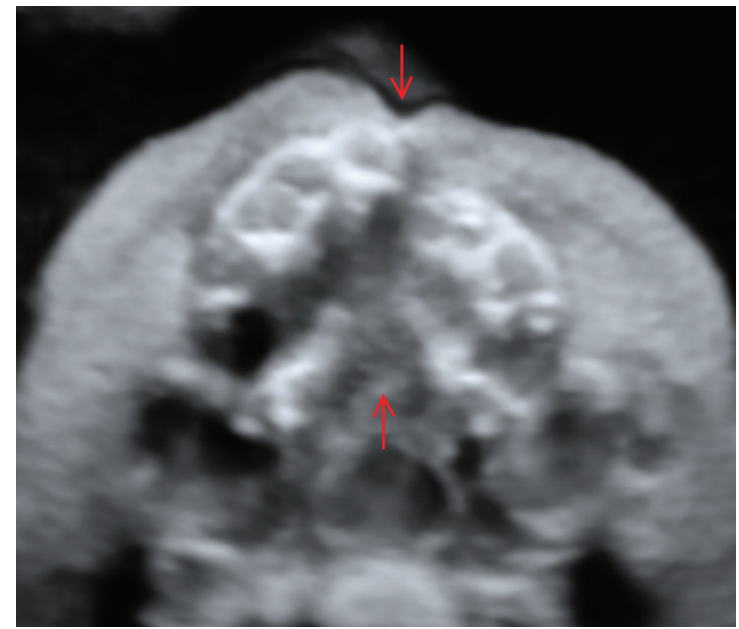

Figure 5 Three-dimensional ultrasound of cleft lip and palate (arrows) at 29 weeks of gestation.

Note: Axial acquisition.

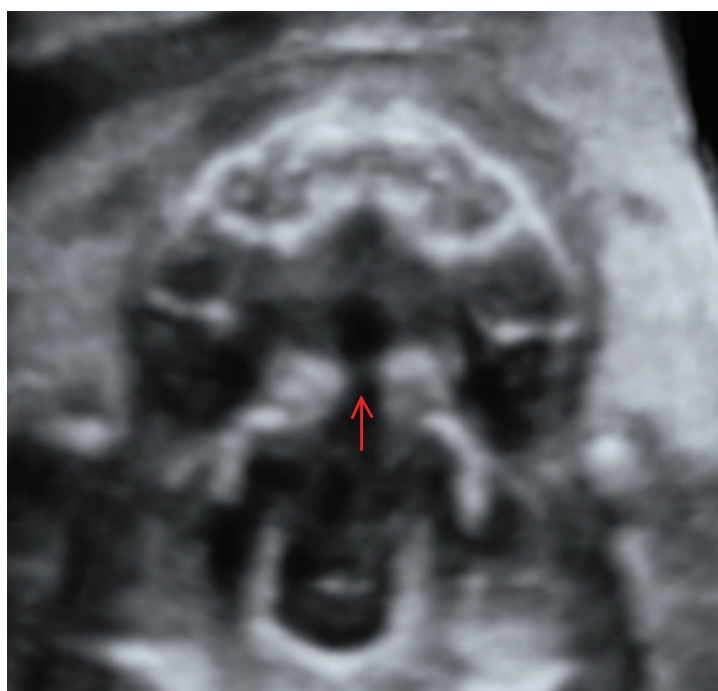

Figure 6 Three-dimensional ultrasound of cleft palate (arrow) at 28 weeks of gestation. Note: Axial acquisition.

bi-dimensional ultrasound permits us to clarify the clinical utility of both techniques. It is emphasized that, in clinical practice, practitioners should always make the distinction between imaging for screening or diagnostic purposes. This distinction might be of great value in aiding communication with parents, and within the prenatal multidisciplinary counseling team. The practitioner should clearly communicate under which circumstances the fetus has been examined, and which method, ie, bi-dimensional or three-dimensional ultrasound, has been used.

With regard to the national guidelines commonly used in our country, we continue to consider that bi-dimensional ultrasound visualization of the nostrils and lips is sufficient

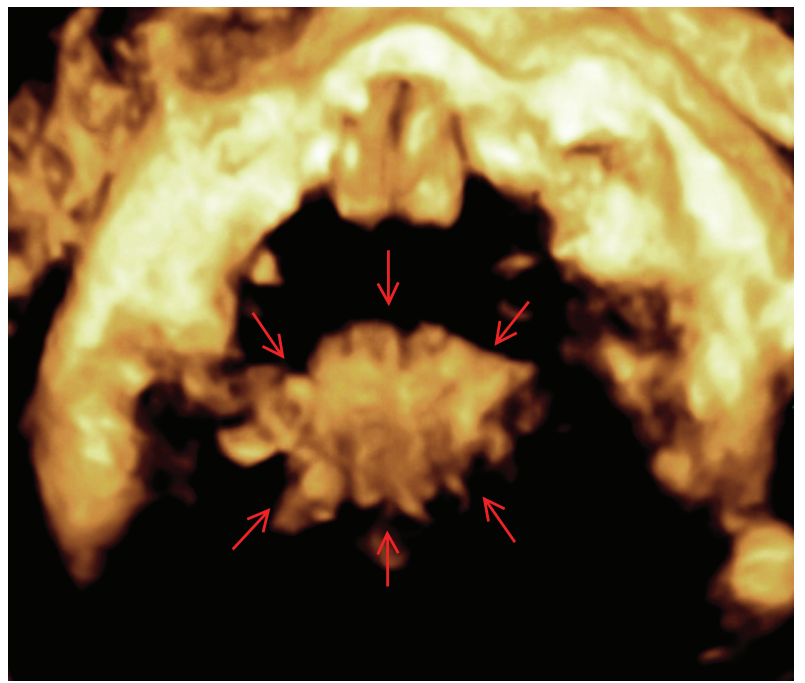

Figure 7 Three-dimensional ultrasound of the soft palate (arrows) at 32 weeks of gestation.

Note: Axial acquisition and $30^{\circ}$ post-acquisitional rotation. 


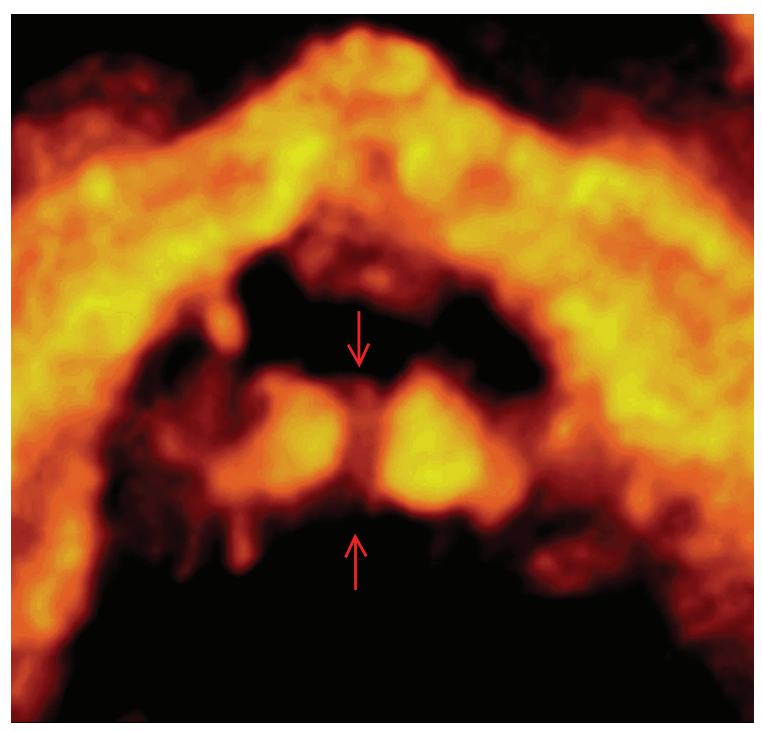

Figure 8 Three-dimensional ultrasound of the cleft soft palate (arrows) at 29 weeks of gestation.

Note: Axial acquisition and $30^{\circ}$ post-acquisitional rotation.

for screening of the fetal face. The coronal view screens for the most frequent facial malformation, ie, cleft lip. ${ }^{58}$ This bi-dimensional view should be present in all screening reports. When screening using the bi-dimensional view is normal, we consider that the three-dimensional view does not provide additional information. In contrast, when cleft lip is screened for, a three-dimensional view can specify the degree of extension of the cleft into the nostrils (personal observation).

In the case of screening for an anomaly of the face or other organs, or where there is a family history, the practitioner is faced with a diagnostic situation. In this case, recent French guidelines require supplementary bi-dimensional visualization of the profile, orbits, and lenses. ${ }^{7}$ Analysis of these morphological elements ensures that additional information about other frequent facial anomalies, ie, retrognathism and anophthalmia/microphthalmia, will be collected. ${ }^{48}$
Visualization of these elements orientates the diagnostic considerations and reduces the risk of error. Additionally, several recent publications consider that complementary three-dimensional ultrasound assists analysis of the profile ${ }^{46}$ and the eyes. ${ }^{26}$ In our opinion, three-dimensional analysis of the bony profile at the maxilla-nasion-mandible angle as proposed by De Jong-Pleij et $\mathrm{al}^{46}$ is an interesting tool because it seems coherent, objective, and easy to assess.

Furthermore, visualization of other facial elements, ie, the ears, and the hard and the soft palate provide additional information about eventual associated anomalies. Biometrics of the ears ${ }^{19}$ and the integrity of the hard palate ${ }^{79}$ can be visualized by bi-dimensional ultrasound. Several publications and the clinical experience of our team indicate that analysis of these structures can be improved by use of three-dimensional ultrasound. ${ }^{73,80,85,90,91}$ Three-dimensional morphological analysis of the ears is interesting because of the clear and detailed visualization. Three-dimensional visualization of the hard palate probably provides better definition than bi-dimensional ultrasound. Without doubt, visualization of the soft palate is only accessible by three-dimensional and not bi-dimensional ultrasound. ${ }^{89}$ Table 1 shows the most important malformations and aspects determined on bi-dimensional ultrasound versus three-dimensional ultrasound.

Concerning comparison with MRI, past publications indicate promising results, ${ }^{10-12}$ but future investigations should show more convincing results. To date, in our clinical experience, three-dimensional ultrasound is accurate, defined, realistic, and rarely erroneous. MRI does not add complementary information when investigating the fetal face. The differences between bi-dimensional and three-dimensional ultrasound in terms of financial costs have not yet been quantified; in France, public illness insurance does not distinguish between screening and diagnostic ultrasound, and the financial cost of

Table I Facial malformations on bi-dimensional versus three-dimensional ultrasound

\begin{tabular}{|c|c|c|}
\hline Facial parameter & Malformation on 2D US & Malformation on 3D US \\
\hline Ear & Anotia/microtia & Subtle morphological anomalies \\
\hline \multirow[t]{2}{*}{ Eye } & Anophthalmia/microphthalmia & Anophthalmia/microphthalmia \\
\hline & Hypertelorism/hypotelorism & Hypertelorism/hypotelorism \\
\hline \multirow[t]{4}{*}{ Profile } & Flat profile & Flat profile \\
\hline & Retrognathism & Retrognathism \\
\hline & Absent/short nasal bone & Absent/short nasal bone \\
\hline & & Subtle anomalies of the angles \\
\hline Lips & Cleft lip & Cleft lip and its extension to nostrils \\
\hline Primary palate & Cleft alveolus & Cleft alveolus \\
\hline Secondary palate & Cleft lip and palate, cleft palate & Cleft lip and palate, cleft palate and their extension \\
\hline Soft palate & - & Submucosal cleft soft palate \\
\hline
\end{tabular}

Abbreviations: 2D US, bi-dimensional ultrasound; 3D US, three-dimensional ultrasound. 
additional time spent on more exhaustive examination cannot be taken into account.

Ramos et $\mathrm{al}^{92}$ found that: use of three-dimensional ultrasound for visualization of the profile took about 60 seconds and about 73 seconds for the primary palate; that this period might be shorter in expert hands; and a standardized teaching program might improve the use and accuracy of bi-dimensional ${ }^{93}$ and three-dimensional ultrasound. ${ }^{92}$ However, there are no statistics permitting a precise comparison of the financial aspects of the two approaches.

We estimate that, in comparison with bi-dimensional ultrasound, use of three-dimensional ultrasound might prolong the examination by 30-60 seconds. Bi-dimensional ultrasound analysis of the hard or soft palate, ${ }^{73,80,85,89}$ as usually employed by our team, provides satisfactory information in the second and third trimester. As already published and confirmed by our clinical experience, information about the anatomy of the palate and its accuracy in the case of cleft lip and palate satisfies our prenatal counseling colleagues, especially the pediatric surgeons, because the information is mostly exact. Although these techniques are employed exclusively by experts, they can be used by regular practitioners after appropriate tuition. In our opinion, universal use of these techniques might accelerate individual learning curves, even for screening. Teaching and improvement in learning can probably be ameliorated by ultrasound techniques which allow to work "offline", ie, to analyse the images after acquisition in presence of an expert. ${ }^{94}$

In the future, comparisons of the different threedimensional ultrasound techniques when evaluating the hard palate (by distinguishing between screening or diagnosis and by specifying analysis of cleft of the alveolar ridge of the maxilla, cleft lip and palate, or cleft palate alone) and the angles of the profile are needed in order to find a consensus in these challenging prenatal counseling situations. In regard of the actual analysis of the recent 3D techniques, we think that they constantly permit to ameliorate the imaging of the fetal face in difficult diagnostic conditions. In contrast, the techniques are not expected to gain diffusion in uncomplicated screening conditions. Prenatal standards should be based on the latest evidence. ${ }^{95}$

\section{Disclosure}

The authors report no conflicts of interest in this work.

\section{References}

1. Jones MC. Prenatal diagnosis of cleft lip and palate: detection rates, accuracy of ultrasonography, associated anomalies, and strategies for counseling. Cleft Palate Craniofac J. 2002;39:169-173.
2. Kürzl B. Anwendung und Beurteilung diagnostischer Test und Screeningverfahren [Use and judgment of diagnostic and screening tests]. In: Schneider H, Husslein P, Schneider KTM, editors. Geburtshilfe [Obstetrics]. Heidelberg, Germany: Springer 2000:99-112. German.

3. Mărginean C, Brînzaniuc K, Mühlfay G, Horvath K, Mărginean O The three-dimensional ultrasonography of the fetal face - history and progress. Rev Med Chir Soc Med Nat Iasi. 2010;114:1058-1063. Romanian.

4. Gonçalves LF, Lee W, Espinoza J, Romero R. Three- and 4-dimensional ultrasound in obstetric practice: does it help? J Ultrasound Med. 2005;24:1599-1624.

5. Manning FA. General principles and applications of ultrasonography. In: Creasy RK, Resnik R, editors. Maternal-Fetal Medicine. 4th ed. Philadelphia, PA: WB Saunders; 1999.

6. Dommergues M, Bessis R, Henrion R. Rapport du Comité national technique de l'échographie de dépistage prénatal: quelles conséquences pour la pratique? [Report of the French Comité national technique de l'échographie de dépistage prénatal (prenatal ultrasound): what are the practical consequences?]. Gynécol Obstet Fertil. 2006;34:1090-1095. French.

7. Rapport du Comité national technique de l'échographie de diagnostic prénatal [Report of the French Comité national technique de l'échographie de dépistage prénatal] (prenatal diagnostic ultrasound) 2010. French. http://www.cngof.asso.fr/D_TELE/100513_rapport_echo.pdf. Accessed May 18, 2010.

8. Johnson DD, Pretorius DH, Budorick NE, Jones MC, Lou KV, Nelson TR. Three-dimensional ultrasound of the fetal lip and primary palate. Radiology. 2000;217:236-239.

9. Mailáth-Pokorny M, Worda C, Krampl-Bettelheim E, Watzinger F, Brugger PC, Prayer D. What does magnetic resonance imaging add to the prenatal ultrasound diagnosis of facial clefts? Ultrasound Obstet Gynecol. 2010;36:445-451.

10. Li XB, Kasprian G, Hodge JC, et al. Fetal ocular measurements by MRI. Prenat Diagn. 2010;30:1064-1071.

11. Wang G, Shan R, Zhao L, Zhu X, Zhang X. Fetal cleft lip with and without cleft palate: comparison between MR imaging and US for prenatal diagnosis. Eur J Radiol. 2011;79:437-442.

12. Manganaro L, Tomei A, Fierro F, et al. Fetal MRI as a complement to US in the evaluation of cleft lip and palate. Radiol Med. 2011;116:1134-1148.

13. Le Vaillant C, Quere MP, David A, Berlivet M, Boog G. Prenatal diagnosis of a 'minor' form of Brachmann-de Lange syndrome by threedimensional sonography and three-dimensional computed tomography. Fetal Diagn Ther. 2004;19:155-159.

14. Haratz K, Vinkler C, Lev D, Schreiber L, Malinger G. Hemifacial microsomia with spinal and rib anomalies: prenatal diagnosis and postmortem confirmation using 3-D computed tomography reconstruction. Fetal Diagn Ther. 2011;30:309-313.

15. Hatanaka AR, Rolo LC, Mattar R, Araujo Júnior E, Nardozza LM, Moron AF. Reference intervals for fetal ear length between 19 and 24 weeks of pregnancy on 3-dimensional sonography. J Ultrasound Med. 2011;30:1185-1190.

16. Shimizu T, Salvador L, Allanson J, Hughes-Benzie R, Nimrod C. Ultrasonographic measurements of fetal ear. Obstet Gynecol. 1992; 80(3 Pt 1):381-384.

17. Alasti F, Van Camp G. Genetics of microtia and associated syndromes. J Med Genet. 2009;46:361-369.

18. Mastroiacovo P, Corchia C, Botto LD, Lanni R, Zampino G, Fusco D. Epidemiology and genetics of microtia-anotia: a registry based study on over one million births. J Med Genet. 1995;32:453-457.

19. Yeo L, Guzman ER, Ananth CV, Walters C, Day-Salvatore D, Vintzileos AM. Prenatal detection of fetal aneuploidy by sonographic ear length. J Ultrasound Med. 2003;22:565-576.

20. Chang CH, Chang FM, Yu CH, Liang RI, Ko HC, Chen HY. Fetal ear assessment and prenatal detection of aneuploidy by the quantitative threedimensional ultrasonography. Ultrasound Med Biol. 2000;26:743-749.

21. Chitkara U, Lee L, Oehlert JW, et al. Fetal ear length measurement: a useful predictor of aneuploidy? Ultrasound Obstet Gynecol. 2002;19: $131-135$. 
22. Ginsberg NA, Cohen L, Dungan JS, Concialdi S, Mangers K, Shulman LP. 3-D ultrasound of the fetal ear and fetal autosomal trisomies: a pilot study of a new screening protocol. Prenat Diagn. 2011;31:311-314.

23. Roth P, Roth A, Clerc-Bertin F, Sommerhalder J, Maillet R. Prenatal ultrasonic measurements of the eye and the interorbital distance. J Gynecol Obstet Biol Reprod. 1999;28:343-351.

24. Jeanty P, Dramaix-Wilmet M, Van Gansbeke D, Van Regemorter N, Rodesch F. Fetal ocular biometry by ultrasound. Radiology. 1982;143: 513-516.

25. Tsai PY, Chen HC, Huang HH, et al. A new automatic algorithm to extract craniofacial measurements from fetal three-dimensional volumes. Ultrasound Obstet Gynecol. 2012;39:642-647.

26. Odeh M, Feldman Y, Degani S, Grinin V, Ophir E, Bornstein J. Fetal eyeball volume: relationship to gestational age and biparietal diameter. Prenat Diagn. 2009;29:749-752.

27. Wong HS, Parker S, Tait J, Pringle KC. Antenatal diagnosis of anophthalmia by three-dimensional ultrasound: a novel application of the reverse face view. Ultrasound Obstet Gynecol. 2008;32:103-105.

28. Benacerraf BR, Nyberg DA. The face and neck. In: Nyberg DA, McGahan JP, Pretorius DH, Pilu G, editors. Diagnostic Imaging of Fetal Anomalies. Philadelphia, PA: Lippincott, Williams \& Wilkins; 2003.

29. Sepulveda W, Wojakowski AB, Elias D, Otaño L, Gutierrez J. Congenital dacryocystocele: prenatal 2- and 3-dimensional sonographic findings. J Ultrasound Med. 2005;24:225-230.

30. Minderer S, Gloning KP, Henrich W, Stöger H. The nasal bone in fetuses with trisomy 21: sonographic versus pathomorphological findings. Ultrasound Obstet Gynecol. 2003;22:16-21.

31. Merz E, Welter C. 2D and 3D ultrasound in the evaluation of normal and abnormal fetal anatomy in the second and third trimester in a level III center. Ultraschall Med. 2005;26:9-16. German.

32. Ghi T, Perolo A, Banzi C, et al. Bi-dimensional ultrasound is accurate in the diagnosis of fetal craniofacial malformations. Ultrasound Obstet Gynecol. 2002;19:543-551.

33. De Jong-Pleij EAP, Ribbert LSM, Tromp E, Bilardo CM. Threedimensional multiplanar ultrasound is a valuable tool in the study of the fetal profile in the second trimester of pregnancy. Ultrasound Obstet Gynecol. 2010;35:195-200.

34. Sonek JD. Nasal bone evaluation with ultrasonography: a marker for fetal aneuploidy. Ultrasound Obstet Gynecol. 2003;22:11-15.

35. Vos FI, De Jong-Pleij EAP, Ribbert LSM, Tromp E, Bilardo CM. Three-dimensional ultrasound imaging and measurement of nasal bone length, prenasal thickness and frontomaxillary facial angle in normal second- and third-trimester. Ultrasound Obstet Gynecol. 2012;39:636-641.

36. Mazzoni GT Jr, Cabral AC, de Lima Faria MM, et al. Ultrasound evaluation of the fetal nasal bone: what is the most appropriate firsttrimester cut-off point for aneuploidy screening? Arch Gynecol Obstet. 2012;285:1263-1270.

37. Sonek JD, Cicero S, Neiger R, Nicolaides KH. Nasal bone assessment in prenatal screening for trisomy 21. Am J Obstet Gynecol. 2006; 195:1219-1230.

38. Persico N, Molina F, Azumendi G, Fedele L, Nicolaides KH. Nasal bone assessment in fetuses with trisomy 21 at 16-24 weeks of gestation by three-dimensional ultrasound. Prenat Diagn. 2012;32:240-244.

39. Benoit B, Chaoui R. Three-dimensional ultrasound with maximal mode rendering: a novel technique for the diagnosis of bilateral or unilateral absence or hypoplasia of nasal bones in second-trimester screening for Down syndrome. Ultrasound Obstet Gynecol. 2005;25:19-24.

40. Odibo AO, Sehdev HM, Stamilio DM, Cahill A, Dunn L, Macones GA. Defining nasal bone hypoplasia in second-trimester Down syndrome screening: does the use of multiples of the median improve screening efficacy? Am J Obstet Gynecol. 2007;197:361. e1-e4.

41. Gonçalves LF, Espinoza J, Lee W, et al. Phenotypic characteristics of absent and hypoplastic nasal bones in fetuses with Down syndrome: description by 3-dimensional ultrasonography and clinical significance. J Ultrasound Med. 2004;23:1619-1627.
42. Persico N, Borenstein M, Molena F, Azumendi G, Nicolaides KH. Prenasal thickness in trisomy-21 fetuses at 16-24 weeks of gestation. Ultrasound Obstet Gynecol. 2008;32:751-754.

43. De Jong-Pleij EA, Vos FI, Ribbert LS, Pistorius LR, Tromp E, Bilardo CM. Prenasal thickness-to-nasal bone length ratio: a strong and simple second- and third-trimester marker for trisomy 21. Ultrasound Obstet Gynecol. 2012;39:185-190.

44. Captier G, Faure JM, Bäumler M, Canovas F, Demattei C, Daures JP. Prenatal assessment of the antero-posterior jaw relationship in human fetuses: from anatomical to ultrasound cephalometric analysis. Cleft Palate Craniofac J. 2011;48:465-472.

45. Molina AF, Persico N, Borenstein M, Sonek J, Nicolaides KH. Frontomaxillary facial angle in trisomy 21 fetuses at 16-24 weeks of gestation. Ultrasound Obstet Gynecol. 2008;31:384-387.

46. De Jong-Pleij EA, Ribbert LSM, Manten GTR, Tromp E, Bilardo CM. Maxilla-nasion-mandible angle: a new method to assess profile anomalies in pregnancy. Ultrasound Obstet Gynecol. 2011;37:562-569.

47. Palit G, Jacquemyn Y, Kerremans M. An objective measurement to diagnose micrognathia on prenatal ultrasound. Clin Exp Obstet Gynecol. 2008;35:121-123.

48. Luedders DW, Bohlmann MK, Germer U, Axt-Fliedner R, Gembruch U, Weichert J. Fetal micrognathia: objective assessment and associated anomalies on prenatal sonogram. Prenat Diagn. 2011;31: $146-151$.

49. Chitty LS, Campbell S, Altman DG. Measurement of the fetal mandible - feasibility and construction of a centile chart. Prenat Diagn. 1993;13:749-756.

50. Otto C, Platt LD. The fetal mandible measurement: an objective determination of fetal jaw size. Ultrasound Obstet Gynecol. 1991;1:12-17.

51. Rotten D, Levaillant JM, Martinez H, Ducou le Pointe H, Vicaut E. The fetal mandible: a 2D and 3D sonographic approach to the diagnosis of retrognathia and micrognathia. Ultrasound Obstet Gynecol. 2002;19:122-130.

52. Paladini D, Morra T, Teodoro A, Lamberti A, Tremolaterra F, Martinelli P. Objective diagnosis of micrognathia in the fetus: the jaw index. Obstet Gynecol. 1999;93:382-386.

53. Zalel Y, Gindes L, Achiron R. The fetal mandible: an in utero sonographic evaluation between 11 and 31 weeks' gestation. Prenat Diagn. 2006;26:163-167.

54. Roelfsema NM, Hop WC, Wladimiroff JW. Three-dimensional sonographic determination of normal fetal mandibular and maxillary size during the second half of pregnancy. Ultrasound Obstet Gynecol. 2006;28:950-957.

55. Hermann NV, Darvann TA, Sundberg K, Kreiborg S, Jørgensen C. Mandibular dimensions and growth in 11- to 26-week-old Danish fetuses studied by 3D ultrasound. Prenat Diagn. 2010;30:408-412.

56. Royal College of Obstetricians and Gynaecologists. Routine Ultrasound in Pregnancy - Protocol, Standards and Training. A Working Party Report by the RCOG. London, UK: Royal College of Obstetricians and Gynaecologists Press; 2000.

57. American Institute of Ultrasound in Medicine. Standards of performance. Antepartum obstetric ultrasound examination. J Ultrasound Med. 2003;22:1116-1125.

58. Tolarová MM, Cervenka J. Classification and birth prevalence of orofacial clefts. Am J Med Genet. 1998;75:126-137.

59. Levi S, Schaaps JP, De Havay P, Coulon R, Defoort P. End-result of routine ultrasound screening for congenital anomalies: the Belgian Multicentric Study 1984-1992. Ultrasound Obstet Gynecol. 1995;5: 366-371.

60. Romosan G, Henriksson E, Rylander A, Valentin L. Diagnostic performance of routine ultrasound screening for fetal abnormalities in an unselected Swedish population in 2000-2005. Ultrasound Obstet Gynecol. 2009;34:526-533.

61. Crane JP, LeFevre ML, Winborn RC, et al. A randomized trial of prenatal ultrasonographic screening: impact on the detection, management, and outcome of anomalous fetuses. Am J Obstet Gynecol. 1994;171:392-339. 
62. Chitty LS, Hunt GH, Moore J, Lobb MO. Effectiveness of routine ultrasonography in detecting fetal structural abnormalities in a low risk population. BMJ. 1991;303:1165-1169.

63. Hata T, Yonehara T, Aoki S, Manabe A, Hata K, Miyazaki K. Three-dimensional sonographic visualization of the fetal face. AJR Am J Roentgenol. 1998;170:481-483.

64. Kernahan DA, Stark RB. A new classification for cleft lip and cleft palate. Plast Reconstr Surg Transplant Bull. 1958;22:435-441.

65. Langman J. Medical Embryology. Baltimore, MD: The Williams and Wilkins Company; 1985

66. Benacerraf BR, Mulliken JB. Fetal cleft lip and palate: sonographic diagnosis and postnatal outcome. Plast Reconstr Surg. 1993;92: 1045-1051.

67. Tessier P. Anatomical classification of facial, craniofacial and laterofacial clefts. J Maxillofac Surg. 1976;4:69.

68. Christ JE, Meininger MG. Ultrasound diagnosis of cleft lip and cleft palate before birth. Plast Reconstr Surg. 1981;68:854-859.

69. Martínez Ten P, Pérez Pedregosa J, Santacruz B, Adiego B, Barrón E, Sepúlveda W. Three-dimensional ultrasound diagnosis of cleft palate: 'reverse face', 'flipped face' or 'oblique face' - which method is best? Ultrasound Obstet Gynecol. 2009;33:399-406.

70. Rotten D, Levaillant J. Two- and three-dimensional sonographic assessment of the fetal face. 2. Analysis of cleft lip, alveolus and palate. Ultrasound Obstet Gynecol. 2004;24:402-411.

71. Platt L, Devore G, Pretorius D. Improving cleft palate/cleft lip antenatal diagnosis by 3-dimensional sonography: the "flipped face" view. J Ultrasound Med. 2006;25:1423-1430.

72. Campbell S. Prenatal ultrasound examination of the secondary palate. Ultrasound Obstet Gynecol. 2007;29:124-127.

73. Bäumler M, Faure JM, Bigorre M, et al. Accuracy of prenatal threedimensional ultrasound in the diagnosis of cleft hard palate when cleft lip is present. Ultrasound Obstet Gynecol. 2011;38:440-444.

74. Pilu G, Segata M. A novel technique for visualization of the normal and cleft fetal secondary palate: angled insonation and three-dimensional ultrasound. Ultrasound Obstet Gynecol. 2007;29:166-169.

75. Chmait R, Pretorius D, Jones M, et al. Prenatal evaluation of facial clefts with bi-dimensional and adjunctive three-dimensional ultrasonography: a prospective trial. Am J Obstet Gynecol. 2002;187:946-949.

76. Mittermayer C, Blaicher W, Brugger PC, Bernaschek G, Lee A. Foetal facial clefts: prenatal evaluation of lip and primary palate by $2 \mathrm{D}$ and 3D ultrasound. Ultraschall Med. 2004;25:120-125. German.

77. Chen ML, Chang CH, Yu CH, Cheng YC, Chang FM. Prenatal diagnosis of cleft palate by three-dimensional ultrasound. Ultrasound Med Biol. 2001;27:1017-1023.

78. Babcook CJ, McGahan JP, Chong BW, Nemzek WR, Salamat MS. Evaluation of fetal midface anatomy related to facial clefts: use of US. Radiology. 1996;201:113-118.

79. Develay-Morice JE, Hoffet M, Fredouille C, Deschamps F, Mares P. Palate pathology diagnosed in fetus. Ultrasound Obstet Gynecol. 2003;22:95-96.

80. Faure JM, Captier G, Bäumler M, Boulot P. Sonographic assessment of normal fetal palate using three-dimensional imaging: a new technique. Ultrasound Obstet Gynecol. 2007;29:159-165.
81. Campbell S, Lees C, Moscoso G, Hall P. Ultrasound antenatal diagnosis of cleft palate by a new technique: the 3D "reverse face" view. Ultrasound Obstet Gynecol. 2005;25:12-18.

82. Sommerlad M, Patel N, Vijayalakshmi B, et al. Detection of lip, alveolar ridge and hard palate abnormalities using bi-dimensional ultrasound enhanced with the three-dimensional reverse-face view. Ultrasound Obstet Gynecol. 2010;36:596-600.

83. Egglin TK, Feinstein AR. Context bias. A problem in diagnostic radiology. JAMA. 1996;276:1752-1755.

84. McGahan MC, Ramos GA, Landry C, et al. Multislice display of the fetal face using 3-dimensional ultrasonography. J Ultrasound Med. 2008;27:1573-1581

85. Faure JM, Bäumler M, Bigorre M, Captier G, Boulot P. Prenatal diagnosis of an isolated incomplete $\mathrm{V}$-shaped cleft palate using a new three-dimensional ultrasound technique investigation. Surg Radiol Anat. 2007;29:695-698.

86. Sepulveda W, Wong AE, Castro F, Adiego B, Martinez-Ten P. Feasibility of 3-dimensional sonographic examination of the fetal secondary palate during the second-trimester anatomy scan. J Ultrasound Med. 2011;30:1619-1624.

87. Maarse W, Bergé SJ, Pistorius L, et al. Diagnostic accuracy of transabdominal ultrasound in detecting prenatal cleft lip and palate: a systematic review. Ultrasound Obstet Gynecol. 2010;35:495-502.

88. Wong HS, Tait J, Pringle KC. Viewing of the soft and the hard palate on routine 3-D ultrasound sweep of the fetal face - a feasibility study. Fetal Diagn Ther. 2008;24:146-154.

89. Faure JM, Bäumler M, Boulot P, Bigorre M, Captier G. Prenatal assessment of the normal fetal soft palate by three-dimensional ultrasound examination: is there an objective technique? Ultrasound Obstet Gynecol. 2008;31:652-656.

90. Pretorius DH, House M, Nelson TR, Hollenbach KA. Evaluation of normal and abnormal lips in fetuses: comparison between threeand bi-dimensional sonography. AJR Am J Roentgenol. 1995;165: 1233-1237.

91. Merz E, Weber G, Bahlmann F, Miric-Tesanic D. Application of transvaginal and abdominal three-dimensional ultrasound for the detection or exclusion of malformations of the fetal face. Ultrasound Obstet Gynecol. 1997;9:237-243.

92. Ramos GA, Kfir M, Lee S, et al. Benefits of a systematic approach in the evaluation of fetal facial 3-dimensional volumes. J Ultrasound Med. 2011;30:473-479.

93. Yang X, Chen M, Wang HF, et al. Learning curve in measurement of fetal frontomaxillary facial angle at 11-13 weeks of gestation. Ultrasound Obstet Gynecol. 2010;35:530-534.

94. Tonni G, Lituania M. OmniView algorithm: a novel 3-dimensional sonographic technique in the study of the fetal hard and soft palates. J Ultrasound Med. 2012;31:313-318.

95. Chalmers I. Scientific inquiry and authoritarianism in perinatal care and education. Birth. 1983;10:151-166.
Reports in Medical Imaging

\section{Publish your work in this journal}

Reports in Medical Imaging is an international, peer-reviewed, open access journal publishing original research, reports, reviews and commentaries on all areas of medical imaging. The manuscript management system is completely online and includes a very quick and fair peer-review system, which is all easy to use.

\section{Dovepress}

Visit http://www.dovepress.com/testimonials.php to read real quotes from published authors. 